This work is licensed under a Creative Commons Attribution License (CC BY 4.0).

\title{
Three new species of herb gall wasps (Hymenoptera: Cynipidae) from Turkey
}

\author{
Musa AZMAZ (1) 1,* \& Yusuf KATILMIȘ @ ( 2 \\ ${ }^{1}$ Laborant \& Veterinary Health Program, Department of Veterinary, Acipayam Vocational High School, \\ Pamukkale University, Acipayam, Denizli, Turkey. \\ ${ }^{2}$ Department of Biology, Faculty of Arts \& Sciences, Pamukkale University, Denizli, Turkey. \\ ${ }^{*}$ Corresponding author: musazmaz@pau.edu.tr \\ 22Email: ykatilmis@pau.edu.tr \\ ${ }^{1}$ urn:1sid:zoobank.org:author:1F3AEDFB-9464-465C-92E9-8096D05D2992 \\ ${ }^{2}$ urn:lsid:zoobank.org:author:DB75240C-1FCF-431F-B35A-DEB03A4A45AD
}

\begin{abstract}
Three new species of herb gall wasps (Cynipidae: Aulacideini and Phanacidini) are described from Turkey. Aulacidea turguti sp. nov. induces galls on Hieracium patentissimum Freyn \& Sint. ex Freyn, 1895 (Asteraceae) and was collected in Gümüşhane province, Phanacis ciceki sp. nov. and Phanacis urhani sp. nov. were collected in Gümüşhane and Ordu Provinces, the former inducing galls on Picris sp. and the latter on Cirsium vulgare (Savi) Ten., 1835-36 (Asteraceae). SEM images, gall photos, distribution, biology, and diagnostic morphological characteristics of the three new species are provided.
\end{abstract}

Key words. Cynipidae, Aulacideini, Phanacidini, Picris, Cirsium, new species.

Azmaz M. \& Katılmış Y. 2021. Three new species of herb gall wasps (Hymenoptera: Cynipidae) from Turkey. European Journal of Taxonomy 757: 152-168. https://doi.org/10.5852/ejt.2021.757.1421

\section{Introduction}

Gall wasps belonging to the family Cynipidae Latreille, 1802 are native to all continents except Antarctica and Australia (species in Australia have been introduced). The vast majority of cynipid species are known from the northern hemisphere (Holarctic Region) (Ronquist et al. 2015). There are more than 1500 known species in the world today, with about 300 species in the Western Palearctic so far (Buffington et al. 2020). The species diversity of herb gall wasps (tribes Aulacideini Nieves-Aldrey, Nylander \& Ronquist, 2015; Aylacini Ashmead, 1903 and Phanacidini Nieves-Aldrey, Nylander \& Ronquist, 2015) is little known, while the tribe Cynipini Latreille, 1802, known as oak gall wasps, has the largest number of species in the family with over 1000 species (Buffington et al. 2020). There is a similar situation seen in Turkish cynipid diversity, where herb gallers are poorly known, with six species of Aulacideini (Aulacidea acroptilonica Tyurebaev, 1979; A. tavakolii Melika, 2008; A. turcica Azmaz \& Katılmış, 2020; Liposthenes kerneri (Wachtl, 1891), Neaylax salviae (Giraud, 1859), Rhodus cyprius (Houard, 1919)), two species of Aylacini (Aylax hypecoi Trotter, 1913; A. minor Hartig, 1840) and one species of Phanacidini (Phanacis hypochoeridis (Kieffer, 1887)) (Azmaz \& Katılmış 2017, 2020). 
Turkey has an important place in terms of herbaceous plant diversity compared to the European continent, and there should potentially be more species of herb gall wasps. In this paper, we describe the diagnostic characters of these herb gall wasps, and the number of herb gall wasp species in Turkey is increased to 12 with three newly-described species.

\section{Material and methods}

Herb galls were collected in the Eastern Black Sea Region of Turkey. Adult cynipids were reared from herb galls in the laboratory. The emergence dates of the specimens were recorded daily. The adults were preserved in $75 \%$ ethanol, then specimens were air dried and card-mounted before identification. Specimens were examined using a stereo microscope (Leica S8 APO) + camera (BAB, TCA-16.0C). We followed Ronquist \& Nordlander (1989) and Ronquist (1995) for structural terminology, Melika (2006) for measurement definitions, and Harris (1979) for surface sculpture descriptions. The cynipids were identified using the keys of Melika (2006) and Azmaz \& Katılmış (2020) for Aulacidea Ashmead, 1897. Some specimens were dissected for Scanning Electron Microscopy (SEM) images, with dissected adult parts mounted onto a stub with copper tape for SEM preparation. Gold-coated specimens were examined with a Zeiss Supra 40VP SEM with 10-20 KV voltage at the Advanced Research Laboratory, Pamukkale University. The holotypes and paratypes are deposited at the Entomology Research Laboratory, Pamukkale University (PAU), Denizli, Turkey.

\section{Results}

Class Insecta Linnaeus, 1758

Order Hymenoptera Linnaeus, 1758

Suborder Apocrita Latreille, 1810

Superfamily Cynipoidea Latreille, 1802

Family Cynipidae Latreille, 1802

Subfamily Cynipinae Latreille, 1802

Tribe Aulacideini Nieves-Aldrey, Nylander \& Ronquist, 2015

Genus Aulacidea Ashmead, 1897

Aulacidea turguti sp. nov. urn:1sid:zoobank.org:act:4D1AB085-3CDB-47DA-9A60-51D0A36306AB

Figs $1-2$

\section{Diagnosis}

Aulacidea turguti sp. nov. seems most closely related to A. subterminalis Niblett, 1946 and A. pilosellae (Kieffer, 1901) based on the identification key (Melika 2006). In A. turguti sp. nov. the malar space is 0.8 times as long as height of eye; POL 2.2-2.3 times as long as LOL and 3.0-3.1 times as long as diameter of lateral ocellus; clypeus trapezoid, smooth, a median incision absent; anterior tentorial pits distinct, small; clypeo-pleurostomal line indistinct; F1 1.6 times as long as pedicel; placodeal sensilla on F2F11; scutum uniformly delicately alutaceous; scutellar foveae ovate, much broader than high, smooth, shining; dorsellum invisible or absent; lateral propodeal carinae slightly converging inwards in the most posterior part, with setae; nucha long; radial cell opened, veins R1 and Rs reaching anterior margin of wing, but R1 not extending along margin (in some specimens, vein along wing margin very indistinct, weakly pigmented or very thin pigmented, not easily visible); Rs $+M$ of fore wing extending to $2 / 3$ of distance between areolet and basalis; tergite 3 with micropunctures reaching anterior margin of tergite dorsally, with band of micropunctures dorsally (in a few specimens, sparse micropunctures narrowing towards lateral margin of tergite) and without micropunctures in lateral and ventral parts of tergite, while in A. subterminalis malar space 0.3-0.4 times as long as height of eye; POL 1.9 times as long as LOL and 
2.8 times as long as diameter of lateral ocellus; clypeus rectangular, delicately alutaceous, ventral margin slightly incised medially; anterior tentorial pits indistinct, small; clypeo-pleurostomal line distinct; F1 1.9 times as long as pedicel; placodeal sensilla on F3-F11; scutum uniformly delicately coriaceous, with transverse sculpture; scutellar foveae distinctly elongated, much higher than broad, smooth, shining; dorsellum delicately coriaceous, medially very narrow; lateral propodeal carinae straight, without setae; nucha short; radial cell closed, however vein along wing margin indistinct, weakly pigmented;

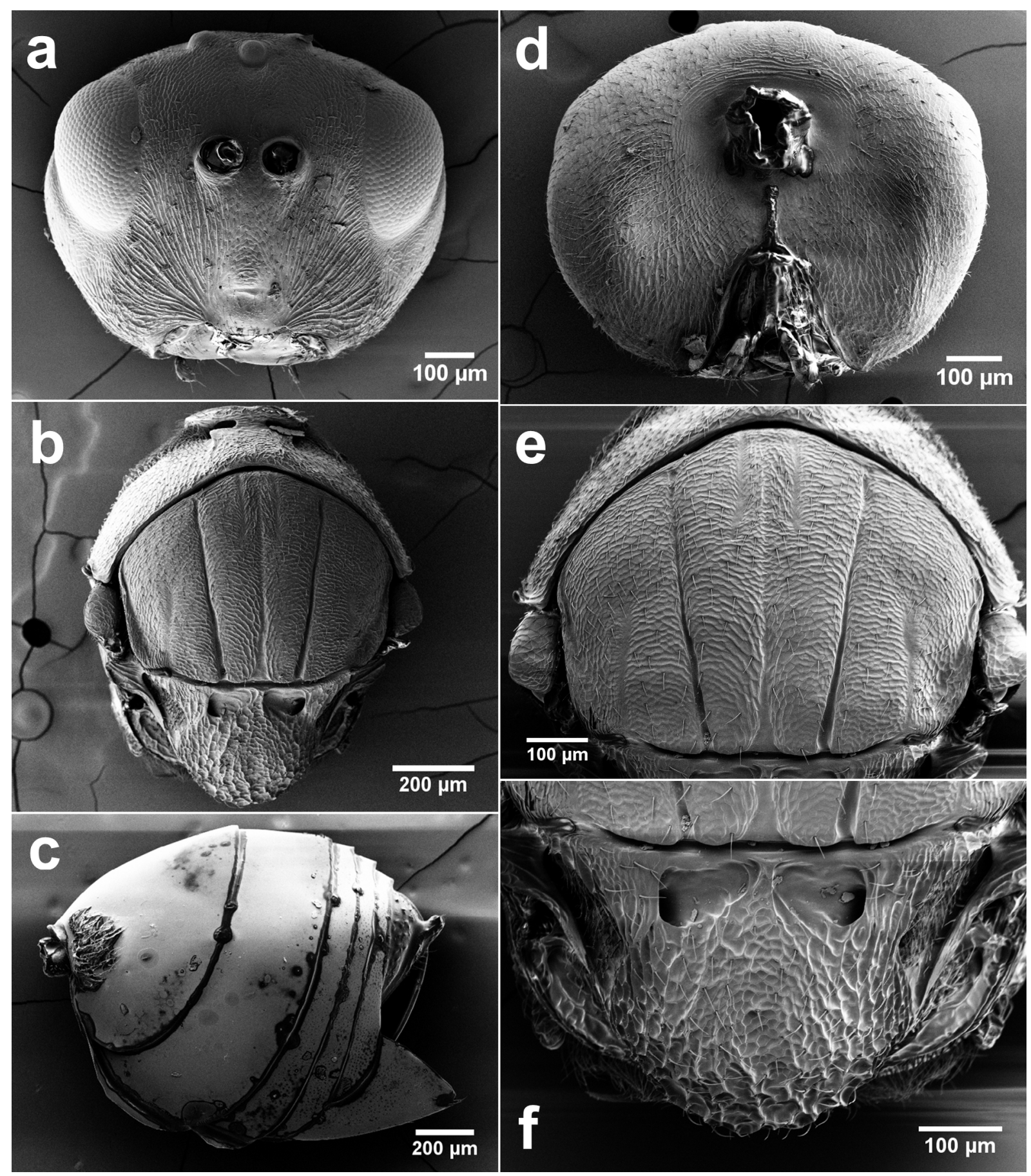

Fig. 1. Aulacidea turguti sp. nov.,, . a. Head in anterior view. b. Mesosoma in dorsal view. c. Metasoma in lateral view. d. Head in posterior view. e. Scutum in dorsal view. f. Scutellum in dorsal view. 
Rs $+\mathrm{M}$ of fore wing distinctly reaching basal vein; tergite 3 with punctures reaching anterior margin of tergite dorsally, with band of punctures lateralo-dorsally. In addition, the gall of $A$. turguti sp. nov is multilocular and has small oval larval chambers inside stem of $H$. patentissimum, while inconspicuous galls of A. subterminalis develop under leaf rosette of Hieracium spp., more rarely on main vein of leaf.

\section{Etymology}

In honour of Prof. Dr Turgut Tok who is a senior Turcologist.

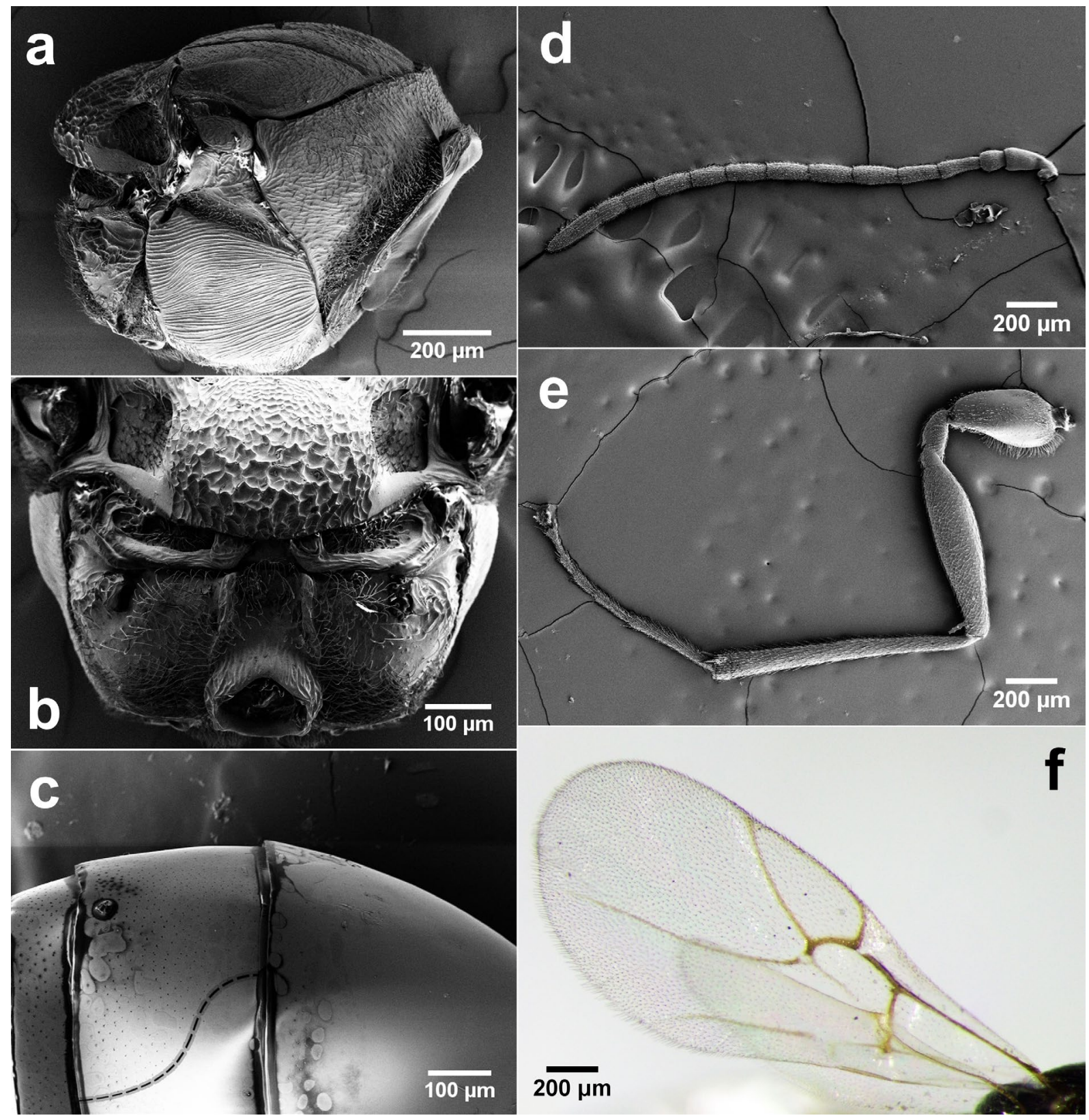

Fig. 2. Aulacidea turguti sp. nov., $q$. a. Mesosoma in lateral view. b. Mesosoma in posterior view. c. Metasomal tergites T2, T3 and T4. d. Antenna. e. Leg. f. Radial cell of forewing. 


\section{Type material}

\section{Holotype}

TURKEY • ' ; Gümüşhane Province, Kürtün, Elmalı; 40³7' N, 3904' E; 1010 m a.s.1.; ex Hieracium patentissimum Freyn \& Sint. ex Freyn, 1895 (Asteraceae); M. Azmaz and Y. Katılmış leg.; galls collected 13 Jun. 2019, 24 Sep. 2019, 11 Apr. 2020; adult emerged 20 Apr. 2020; PAU.

Paratypes

TURKEY・ 67 우, 45 $\precsim$; ; Gümüşhane Province; same data as for holotype.

\section{Description}

\section{Female}

Length. : 2.5-2.7 mm ( $\mathrm{n}=9)$.

Colouration. Head and mesosoma black, antenna, mandibles and palpi brown; all coxae, trochanters, femurs brown, tibiae and tarsi lighter. Metasoma dark reddish brown, dorsally to dark brown or black; hypopygium much lighter. Wing veins distinct, dark brown.

HEAD. Delicately coriaceous, with uniformly sparse white setae, 1.95 times as broad as long from above, 1.2 times as broad as high in front view and slightly broader than mesosoma. Gena delicately coriaceous, broadened behind eye, visible ventrally behind eye in front view. Malar space 0.8 times as long as height of eye, with delicate striae, radiating from clypeus and extending to eye. POL 1.2 times as long as OOL, 2.2-2.3 times as long as LOL and 3.0-3.1 times as long as diameter of lateral ocellus. Transfacial distance 1.4 times as long as height of eye and 1.3-1.4 times as long as height of lower face (distance between antennal rim and ventral margin of clypeus); diameter of antennal torulus 2.4 times as long as distance between them and 0.75 times as long as distance between torulus and eye margin. Lower face with delicately interrupted striae radiating from clypeus and reaching eyes and antennal sockets; median elevated area without striae, very delicately coriaceous. Clypeus trapezoid, broader than high, smooth, narrowly projecting medially, median incision absent; anterior tentorial pits small, distinct, epistomal sulcus distinct and clypeo-pleurostomal line indistinct. Frons, vertex and occiput delicately coriaceous, with a few setae.

ANTENNA. 13-segmented; pedicel subglobose, 1.2 times as long as broad; F1 only 1.6 times as long as pedicel and equal to F2; F2 very slightly shorter than F3; F11 2.0-2.1 times as long as F10; placodeal sensilla on F2-F11, absent on F1.

Mesosoma. Convex, 1.2 times as long as high in lateral view, with uniform sparse white setae. Pronotum alutaceous dorsally, very delicately coriaceous-alutaceous laterally, with few short weak wrinkles and relatively dense white setae along antero-lateral edge. Submedian pronotal pits distinct, transverse, separated by a distance slightly more than half width of a pit; pronotal plate alutaceous, delimited in anterior $2 / 3$ of pronotum, without setae. Scutum uniformly delicately alutaceous with sparse setae, broader than long in dorsal view and 1.6 times as long as scutellum. Notauli complete, well-impressed, strongly broader posteriorly; median mesoscutal line long, sometimes reaching pronotum in form of a dark stripe, broad posteriorly and narrowing anteriorly; parapsidal lines reaching slightly above level of tegulae base; anterior parallel lines distinct, 0.3 times as long as length of scutum. Scutellum rugose, slightly broader than long, rounded posteriorly, with some stronger rugae, sculpture towards center of disk more delicate. Scutellar foveae distinctly ovate, broader than high, smooth, shining, without setae, indistinctly delimited posteriorly; separated by central carina. Mesopleuron, including speculum, uniformly, transversely striate. Metapleural sulcus reaching mesopleuron at upper $1 / 3$ of its height; axillar carina with longitudinal striae; axillula with dense setae, well delimited posteriorly; subaxillular bar smooth, shining, posteriorly nearly equal to height of metanotal trough; ventral bar of metanotal trough 
with delicate wrinkles, narrower than height of metanotal trough. Dorsellum invisible or absent; ventral impressed area reaching scutellum; metanotal trough smooth, with dense white setae; ventral impressed area of dorsellum shining with some delicate weak wrinkles. Lateral propodeal carinae uniformly thick, slightly converging inwards in most posterior part, with setae; central propodeal area smooth, with setae; lateral propodeal area smooth, with setae; nucha long, with regular longitudinal sulci.

FORE WING. With distinct brown veins, margin with cilia; veins R1 and Rs reach anterior margin of wing, but R1 not extending along margin (in some specimens, vein along wing margin very indistinct, weakly pigmented or very thinly pigmented, not easily visible); radial cell open, 2.6 times as long as broad; areolet small, distinct, Rs + M extending to $2 / 3$ of distance between areolet and basalis.

Metasoma. Longer than head +mesosoma, much longer than high in lateral view, with large hypopygium; metasomal tergite 2 with a patch of very dense white setae antero-laterally, impunctate; tergite 3 with micropunctures reaching anterior margin of tergite dorsally, with band of micropunctures dorsally (in a few specimens, sparse micropunctures narrowing towards lateral margin of tergite) and without micropunctures in lateral and ventral parts of tergite; subsequent tergites and hypopygium with dense distinct punctures; prominent part of ventral spine of hypopygium very short, with few short sparse setae not extending beyond apex of spine.

\section{Male}

2.0-2.3 mm ( $\mathrm{n}=5)$. Similar to female but antenna 14-segmented, pedicel globose, as broad as long; F1 1.9-2.0 times as long as pedicel, F1 nearly equal to F2, F3, F4 and F5, subsequent flagellomeres slightly shorter, F12 1.9-2.0 times as long as F11; placodeal sensilla on F1-F12.

\section{Biology}

The adult wasps are known to induce galls on Hieracium patentissimum Freyn \& Sint. ex Freyn, 1895 (Asteraceae). Larvae overwinter in the gall, adults emerge next spring, in April.

\section{Distribution}

Only known from Turkey (Gümüşhane).

\section{Gall structure}

The gall develops on the stem of the host plant in an irregular swelling 10-60 $\mathrm{mm}$ in length and 20 $25 \mathrm{~mm}$ in diameter (Fig. 3). The gall is multilocular and has small oval larval chambers inside the stem.

Tribe Phanacidini Nieves-Aldrey, Nylander \& Ronquist, 2015

Genus Phanacis Förster, 1860

Phanacis ciceki sp. nov. urn:1sid:zoobank.org:act:47C3578E-5FB8-44EB-A332-03A374F41FAF

Figs 4-5

\section{Diagnosis}

Based on the identification key of Melika (2006), together with Phanacis cichorii (Kieffer, 1909) and P. lampsanae (Perris, 1873) form a group of species in which notauli distinctly and deeply impressed along entire length; Rs $+\mathrm{M}$ indistinct, weakly pigmented; $\mathrm{R} 1$ reaching wing margin and never extending to half-length of radial cell. Most closely related to P. cichorii, but in P. ciceki sp. nov. all antennal flagellomeres with normal light setae; POL 1.5 times as long as OOL and 3.7 times as long as diameter of lateral ocellus; pronotum rugulose and slightly angled from above view; scutum distinctly broader 


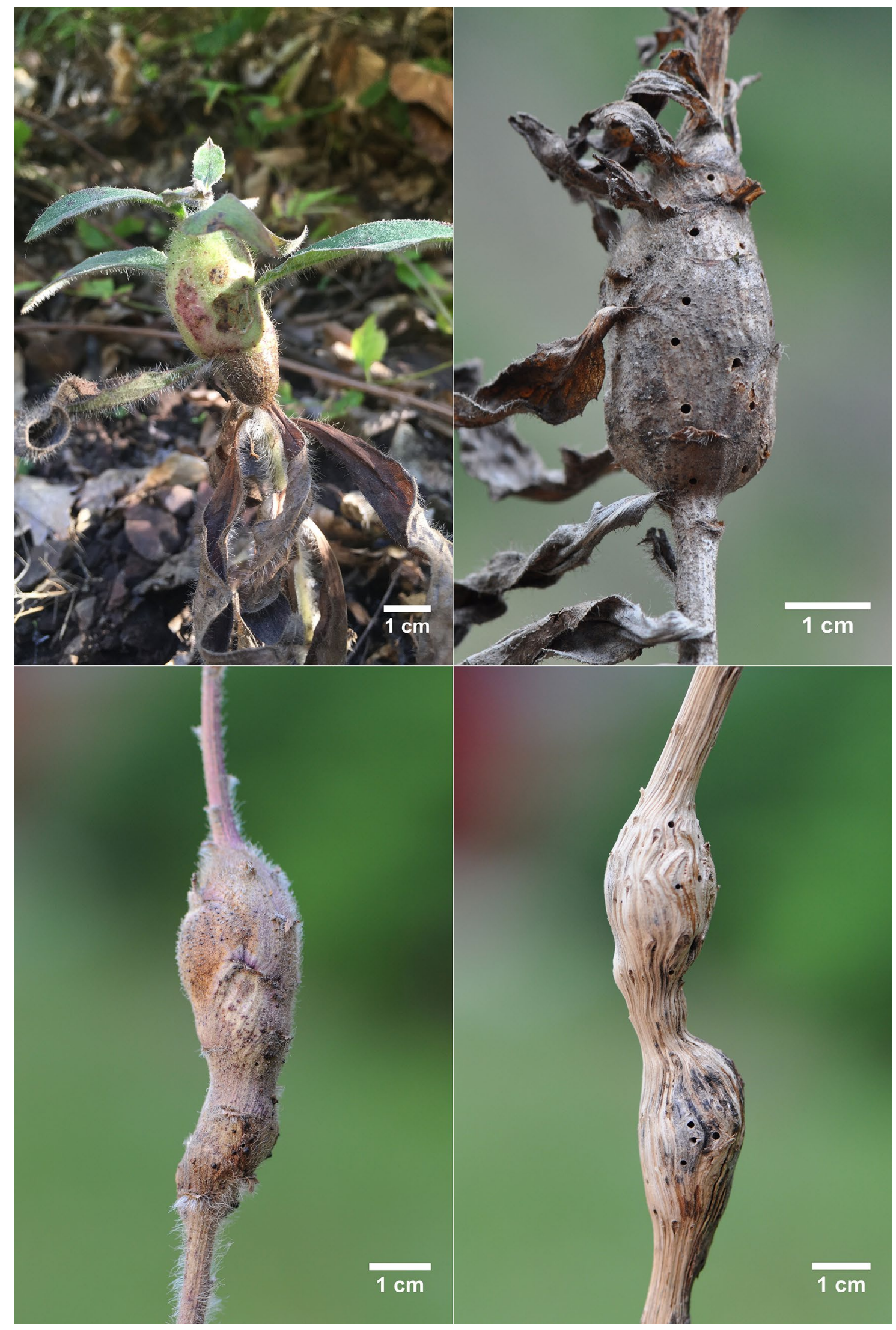

Fig. 3. Galls of Aulacidea turguti sp. nov. on host plant (photos by M. Azmaz). 
than long, 2.3 times as long as scutellum; coriaceous to alutaceous; scutellar foveae separated by a thick central carina; mesopleuron coriaceous, with smooth to wrinkled in the upper half; R1 extending along wing margin to $1 / 3$ length of radial cell; Rs $+\mathrm{M}$ reaching to nearly half-length of distance between areolet and basalis; metasomal tergites all without punctures, while in $P$. cichorii all flagellomeres with long dark setae; POL 1.8 times as long as OOL and 6.3 times as long as diameter of lateral ocellus; pronotum alutaceous and rounded in view from above; scutum slightly longer than broad, 1.3 times as long as scutellum, reticulate; scutellar foveae confluent; mesopleuron reticulate, with some short-interrupted

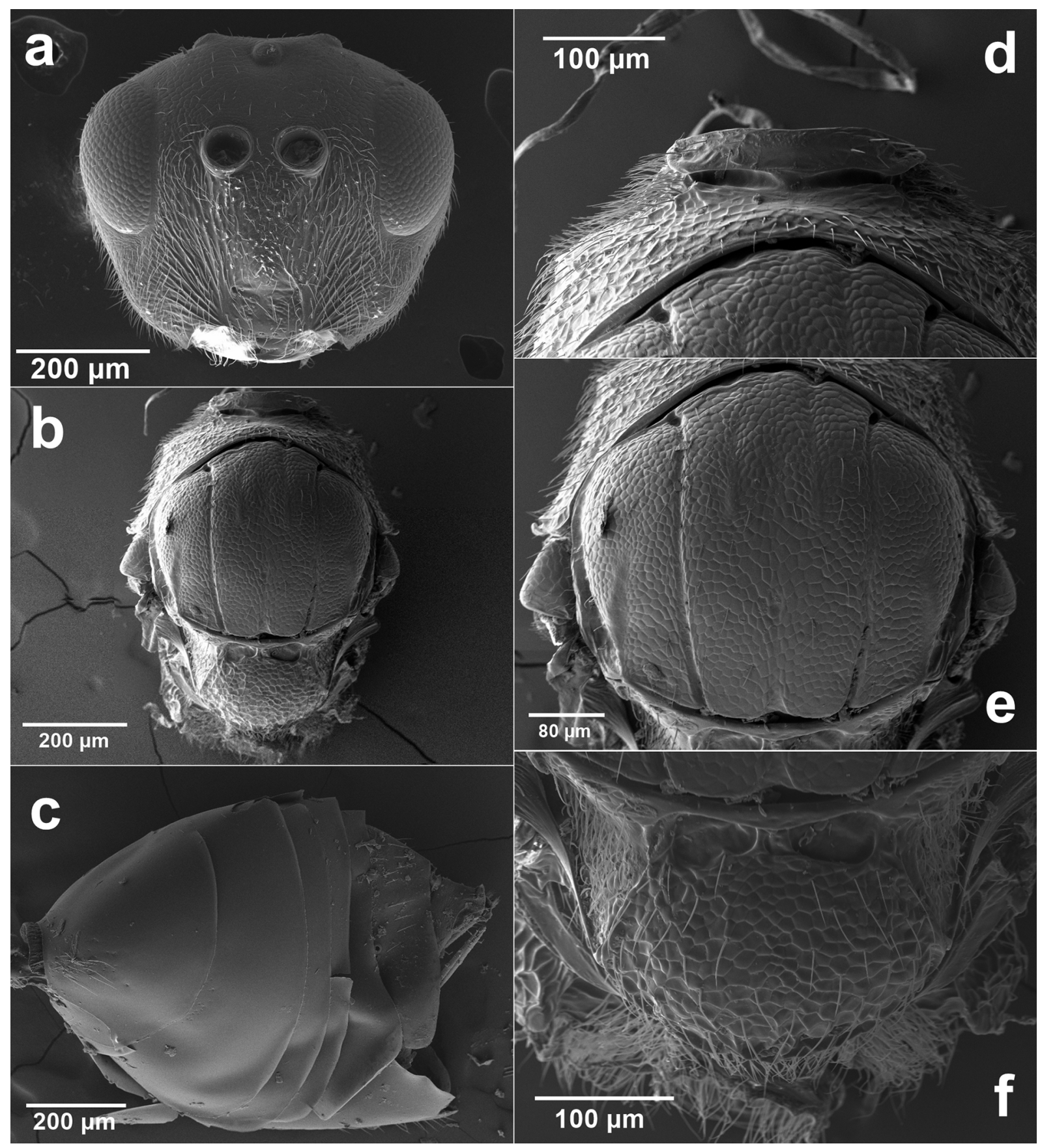

Fig. 4. Phanacis ciceki sp. nov., $q$. a. Head in anterior view. b. Mesosoma in dorsal view. c. Metasoma in lateral view. d. Pronotum in dorsal view. e. Scutum in dorsal view. f. Scutellum in dorsal view. 
transverse striae in the upper half; R1 extending along margin on a short distance; Rs + M never reaching to half-length of distance between areolet and basalis; metasomal tergites only $\mathrm{T} 2$ without punctures. Although $P$. ciceki sp. nov. and P. caulicola (Hedicke, 1939) are similar in terms of use of host plant (Picris sp.), other diagnostic morphological characters allow the separation of $P$. ciceki sp. nov. from $P$. caulicola. In $P$. ciceki sp. nov., notauli distinctly and deeply impressed along entire length; POL 1.5 times as long as OOL and 3.7 times as long as diameter of lateral ocellus; median mesoscutal line weakly extending to $1 / 3$ of scutum length; R1 reaching wing margin and extending along wing margin to $1 / 3$ length of radial cell; the radial cell of the fore wing around 3.0 times as long as broad, while in P. caulicola notauli distinctly impressed only in posterior half, reaching pronotum but very indistinct,

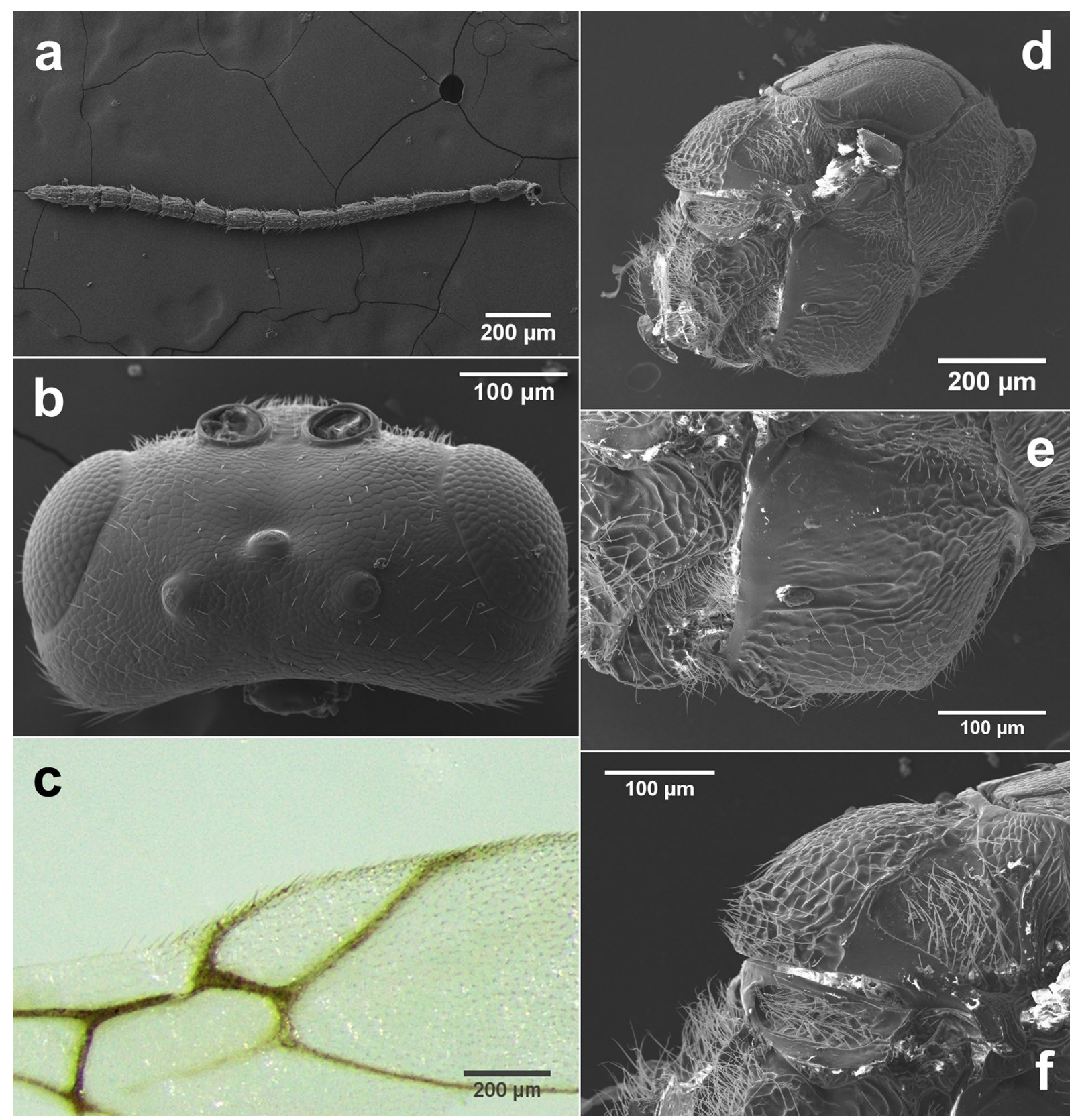

Fig. 5. Phanacis ciceki sp. nov., ․ a. Antenna. b. Head in dorsal view. c. Radial cell of forewing. d. Mesosoma in lateral view. e. Mesopleuron. f. Scutellum in lateral view. 
shallow; POL 1.2 times as long as OOL and 3.0 times as long as diameter of lateral ocellus; median mesoscutal line usually long, extending at least to $1 / 3$ of scutum length; R1 indistinct, depigmented; the radial cell of the forewing 2.5 or less times as long as broad. In addition, the gall of P. ciceki sp. nov. develops as an irregular swelling on stem of Picris sp., while ellipsoid gall of $P$. caulicola develops on stem of Picris, usually with no external deformations.

\section{Etymology}

In honour of Assoc. Prof. Dr Mehmet Çiçek who is an expert botanist.

\section{Type material}

Holotype

TURKEY • O; Gümüşhane Province, Kelkit, Çağlar; $40^{\circ} 05^{\prime}$ N, 39¹7' E; 1650 m a.s.l.; ex Picris sp. (Asteraceae); M. Azmaz and Y. Katılmış leg.; gall collected 21 Feb. 2018; adult emerged May 2018; PAU.

\section{Paratype}

TURKEY • 1 क; Gümüşhane Province; same collection data as for holotype; PAU.

\section{Description}

\section{Female}

LENGTH. 1.8-2.0 $\mathrm{mm}$.

Colouration. Head and mesosoma black; mandibles and palpi dark brown; antenna brown, except much lighter pedicel and F1, and scape dark brown. Legs chestnut brown, with darker coxa and proximal tarsomeres. Metasoma chestnut brown, with much darker to black posterior tergites, hypopygium light brown to orange. Wing veins pale brown.

HeaD. Delicately coriaceous to alutaceous, with uniformly sparse white setae, 1.9 times as broad as long from above, 1.15 times as broad as high and slightly broader than mesosoma. Gena alutaceous, not broadened behind eye; not visible behind eye in front view. Malar space 0.7 times as long as height of eye, with short interrupted strong striae, radiating from clypeus and nearly reaching inner margin of eye. POL 1.5 times as long as OOL; 2.4 times as long as LOL and 3.7 times as long as diameter of lateral ocellus. Transfacial distance 1.4-1.5 times as long as height of eye; diameter of antennal torulus 1.5-1.6 times as long as distance between them and 0.9 times as long as distance between torulus and eye margin. Lower face with interrupted striae, radiating from clypeus and nearly reaching eye and antennal sockets, median elevated area very slightly coriaceous. Clypeus alutaceous to smooth, rectangular, 1.5 times as high as broad; with slightly distinct anterior tentorial pits and epistomal sulcus, clypeo-pleurostomal line indistinct, ventrally rounded, slightly projecting over mandibles. Frons, vertex and occiput coriaceous to alutaceous. Postocciput around occipital foramen not impressed, alutaceous.

ANTENNA. 14-segmented; pedicel 1.6 times as long as broad; F1 2.1 times as long as pedicel and 1.5 times as long as F2, F2 slightly shorter than F3; flagellomeres with normal light setae; placodeal sensilla on all flagellomeres.

Mesosoma. Convex, longer than high in lateral view, with very sparse white setae. Pronotum rugulose and slightly angled from above view, with dense setae along antero-lateral edge. Submedian pronotal pits in form of narrow transverse impressions, without median carina. Scutum distinctly broader than long, 2.3 times as long as scutellum; coriaceous to alutaceous. Notauli distinctly and deeply impressed along entire length; median mesoscutal line weakly extending to $1 / 3$ of scutum length; parapsidal lines narrow, indistinct, reaching tegula level; anterior parallel lines narrow, indistinctly extending to $1 / 3$ of 
scutum length. Scutellum distinctly broader than long, rounded posteriorly; dull rugose along sides and posteriorly, with more delicate coriaceous sculpture towards centre of disk. Scutellar foveae separated by a thick central carina. Mesopleuron coriaceous, smooth to wrinkled in upper half; mesopleural triangle wrinkled, with white setae. Metapleural sulcus reaching mesopleuron at upper $1 / 3$ of its height; axillula with white setae; subaxillular bar smooth, shining, as broad as height of metanotal trough; metapleuron rugose. Dorsellum smooth, shining, narrow medially. Propodeum rugose, lateral propodeal carinae uniformly thick, subparallel; central propodeal area rugose; lateral propodeal area rugose, with sparse white setae.

FORE WING. Margin with long cilia; R1 reaching wing margin and extending along wing margin to $1 / 3$ length of radial cell; radial cell partially closed, around 3.0 times as long as broad, areolet absent, Rs $+\mathrm{M}$ indistinct, weakly pigmented, reaching to nearly half length of distance between areolet and basalis. Tarsal claws without basal lobe.

Metasoma. Longer than high in lateral view; metasomal tergite 2 with a few setae antero-laterally; all tergites and hypopygium without punctures; prominent part of ventral spine of hypopygium short, with relatively long white setae.

\section{Male \\ Unknown.}

\section{Biology}

Only females are known. The adult wasps are known to induce galls on Picris sp. (Asteraceae). The only cynipid species previously known to gall this host is $P$. caulicola. Larvae overwinter in the gall, adults emerge next spring, in May.

\section{Distribution}

Only known from Turkey (Gümüşhane).

\section{Gall structure}

The gall develops on the stem (Fig. 6), forming a 30-60 mm long irregular swelling. Multilocular. There are small larval cells in the typical form inside the stem, like in many species of Phanacis.

Phanacis urhani sp. nov. urn:1sid:zoobank.org:act:9804711C-52E3-4E4B-989B-A8C0A912F011

Figs $7-8$

\section{Diagnosis}

Together with Phanacis caulicola and $P$. hypochoeridis (Kieffer, 1887) form a group of species in which scutellar foveae separated by a central carina; radial cell partially opened along wing margin. Most closely related to $P$. caulicola, but in $P$. urhani sp. nov. POL 1.8 times as long as OOL and 3.6 times as long as diameter of lateral ocellus; notauli extending to half-length of scutum; median mesoscutal line absent; areolet distinct, while in P. caulicola POL 1.2 times as long as OOL and 3.0 times as long as diameter of lateral ocellus; notauli distinctly impressed only in posterior half, reaching pronotum but very indistinct, shallow; median mesoscutal line usually longer, reaching at least to $1 / 3$ of scutum length; areolet absent.

\section{Etymology}

In honour of Prof. Dr Raşit Urhan who is a senior acarologist. 


\section{Type material}

\section{Holotype}

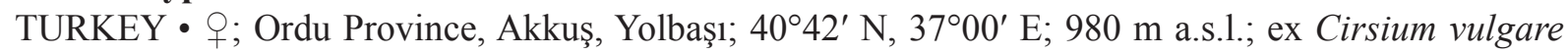
(Savi) Ten., 1835-36 (Asteraceae); M. Azmaz and Y. Katılmış leg.; gall collected 14 Mar. 2019; adult emerged Jul. 2019; PAU.

\section{Paratypes}

TURKEY • 2 q ; Ordu Province; same collection data as for holotype; PAU.

\section{Description}

\section{Female}

\section{LeNGTH. 1.8-2.0 mm.}

Colouration. Head and mesosoma black, metasoma dark brown. Antennae dark brown, legs light brown to yellowish, with darker coxae. Wing veins distinct, brown.

HEAD. Delicately coriaceous to alutaceous, with uniformly sparse white setae, 1.9-2.0 times as broad as long from above, 1.1 times as broad as high and slightly broader than mesosoma. Gena alutaceous, not broadened behind eye; not visible behind eye in front view. Malar space coriaceous, 0.6-0.7 times as long as height of eye, with delicate striae, radiating from clypeus and nearly reaching inner margin of

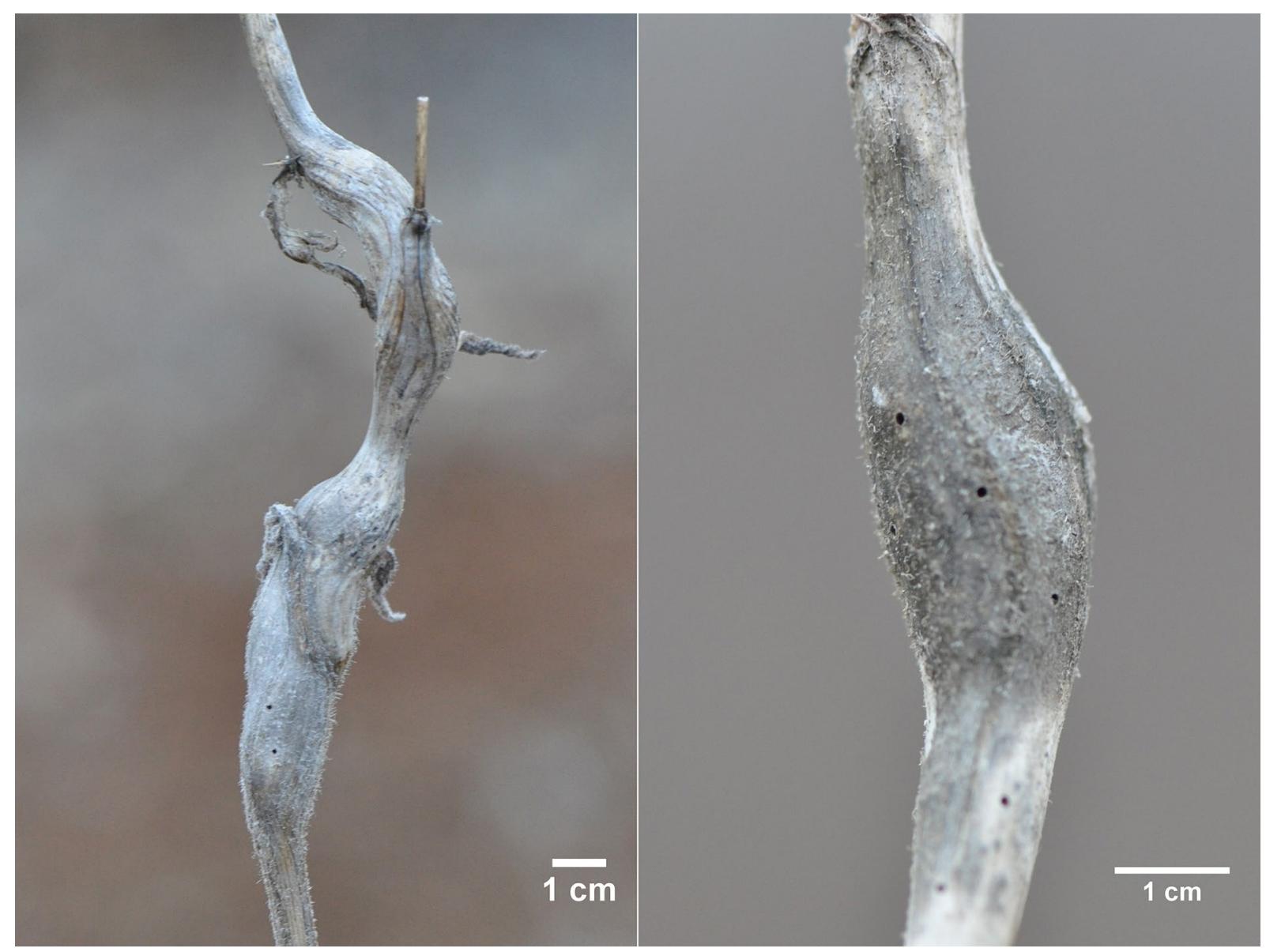

Fig. 6. Phanacis ciceki sp. nov., mature gall on host plant Picris sp. (photos by Y. Katılmış). 
eye. POL 1.8 times as long as OOL; 2.1 times as long as LOL and 3.6 times as long as diameter of lateral ocellus. Transfacial distance 1.3 times as long as height of eye; diameter of antennal torulus 2.2 times as long as distance between them and 0.7 times as long as distance between torulus and eye margin. Lower face with striae, radiating from clypeus and nearly reaching eye and antennal sockets, median elevated area slightly coriaceous with interrupted striae. Clypeus with striae, very narrow and small; with very indistinct anterior tentorial pits, epistomal sulcus and clypeo-pleurostomal line indistinct, ventral margin

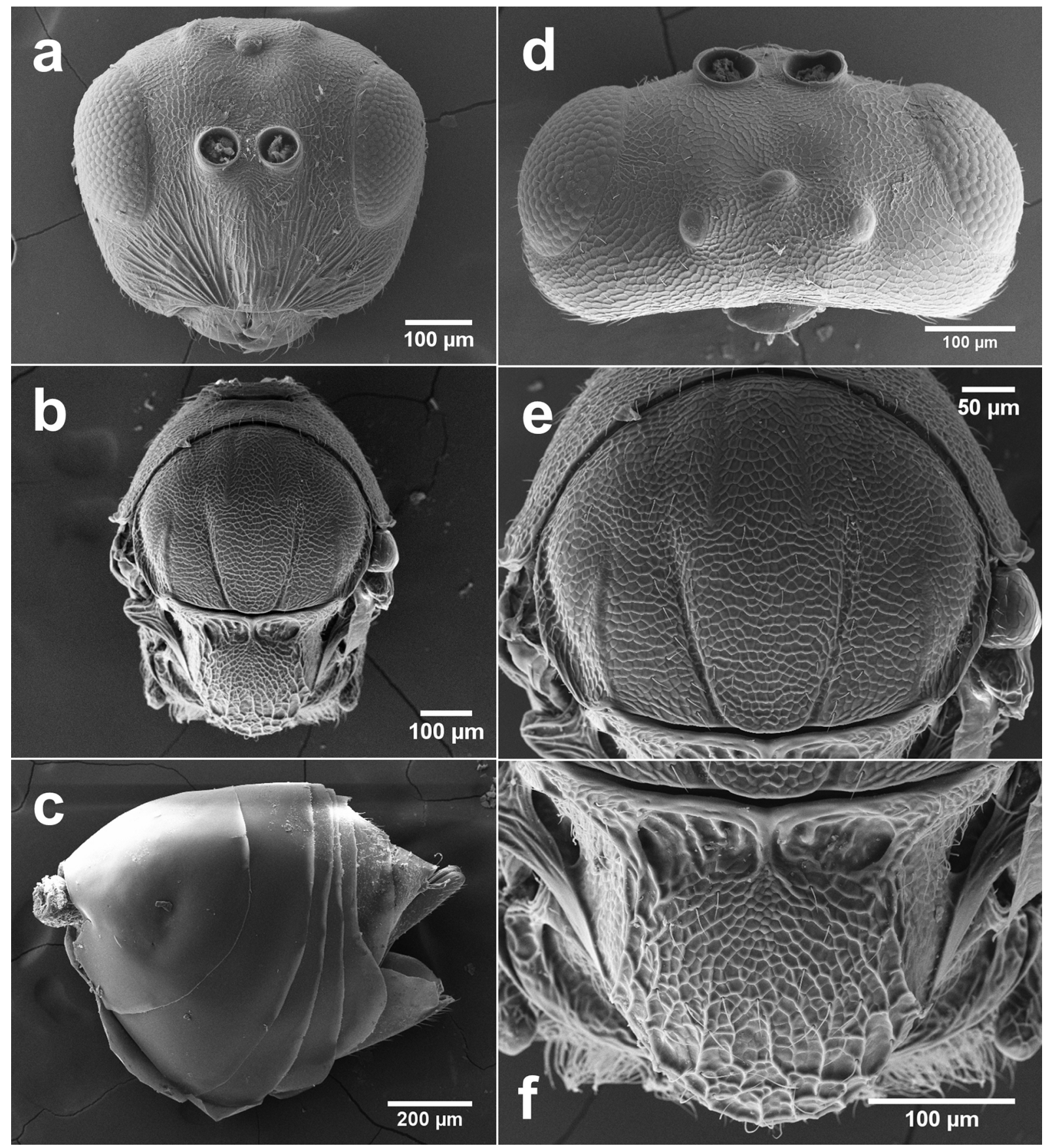

Fig. 7. Phanacis urhani sp. nov.,, . a. Head in anterior view. b. Mesosoma in dorsal view. c. Metasoma in lateral view. d. Head in dorsal view. e. Scutum in dorsal view. f. Scutellum in dorsal view. 
nearly straight. Frons, vertex and occiput delicately coriaceous to alutaceous. Postgena alutaceous, with more dense setae than on front of head.

ANTENNA. 13-segmented, longer than head+mesosoma; pedicel 1.5 times as long as broad; F1 1.9 times as long as pedicel and F1 1.2 times as long as F2, F2 equal F3; placodeal sensilla F2-F11.

Mesosoma. Convex, longer than high in lateral view, with uniform very sparse white setae. Pronotum uniformly alutaceous dorsally, uniformly delicately coriaceous laterally; anterior margin with more dense setae. Submedian pronotal pits indistinct, in form of transverse impression, medially separated

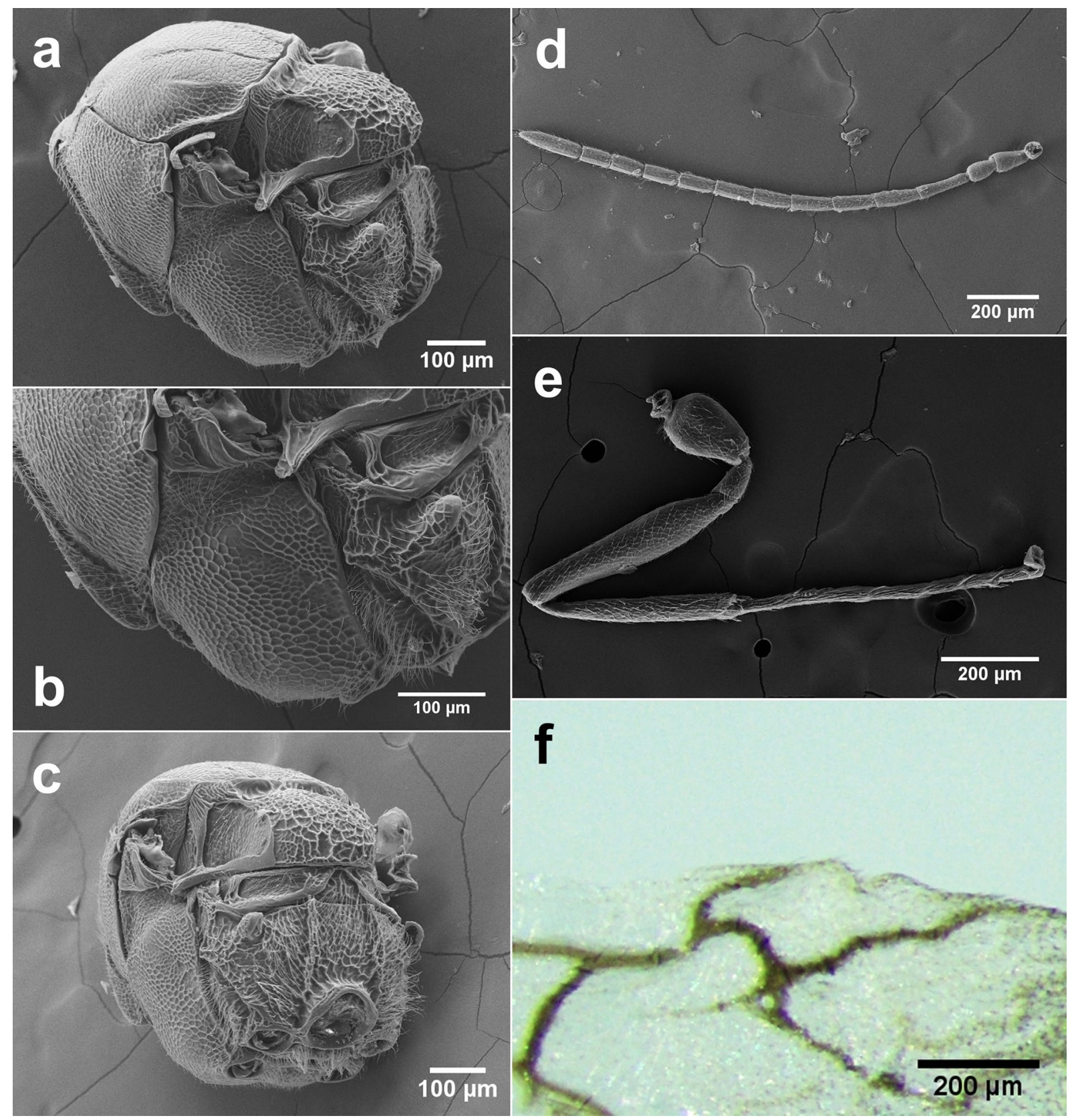

Fig. 8. Phanacis urhani sp. nov., ${ }^{\text {. }}$ a. Mesosoma in lateral view. b. Mesopleuron. c. Mesosoma in posterior view. d. Antenna. e. Leg. f. Radial cell of forewing. 
by a narrow carina. Scutum broader than long, 1.6 times as long as scutellum, uniformly coriaceous to alutaceous. Notauli distinctly impressed, extending to half-length of scutum; median mesoscutal line absent; parapsidal lines narrow, extending slightly above tegula level; anterior parallel lines narrow, distinct, extending to $1 / 3$ of scutum length. Scutellum rounded with very sparse setae, as long as broad; dull rugose along sides and posteriorly, more delicately coriaceous towards centre of disk. Scutellar foveae separated by a central carina, indistinctly delimited posteriorly, with irregular longitudinal rugae. Mesopleuron uniformly reticulate; mesopleural triangle reticulate, with setae. Metapleural sulcus reaching mesopleuron above $1 / 2$ of its height; axillula very narrow wrinkled, with white setae; subaxillular bar smooth, shining, narrower than height of metanotal trough; metapleuron wrinkled, rugose. Dorsellum rugose, very narrowly medially or invisible; ventral impressed area rugose. Propodeum rugose with setae, lateral propodeal carinae subparallel; central propodeal area delicately rugose, with white setae; lateral propodeal area rugose, with dense white setae; propodeal spiracle strongly elevated; nucha with some longitudinal sulci.

FORE WING. Margin with long cilia; R1 reaching wing margin and not extending along margin (open along wing margin), radial cell partially closed, areolet distinct, Rs $+\mathrm{M}$ extending to half of distance between areolet and basalis. Tarsal claws narrow, without basal lobe.

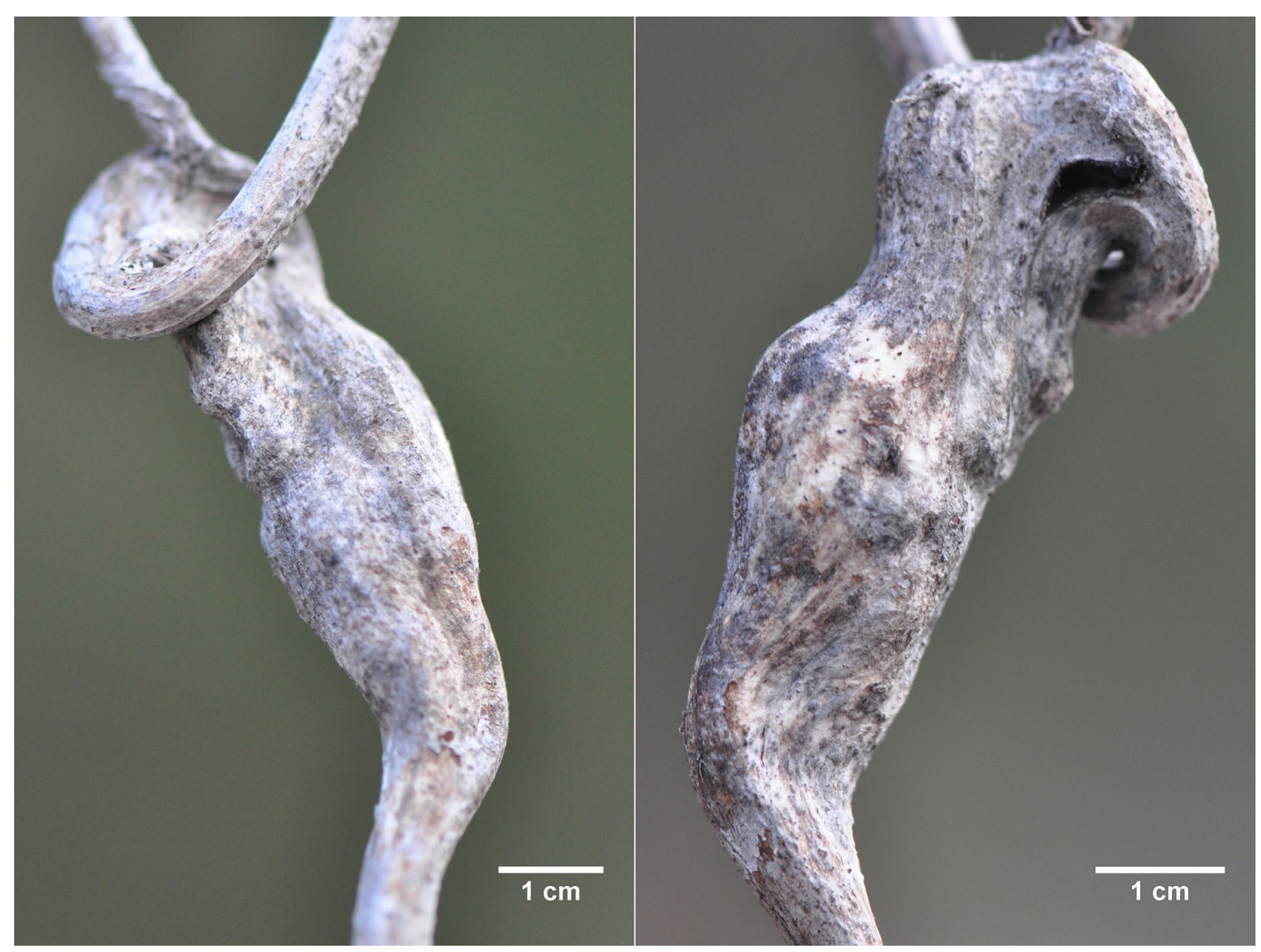

Fig. 9. Phanacis urhani sp. nov., mature gall on host plant, Cirsium vulgare (Savi) Ten. (photos by M. Azmaz). 
Metasoma. Slightly longer than high in lateral view; metasomal tergite 2 without setae anterolaterally and impunctate; only metasomal tergite 6 , subsequent tergites and hypopygium with some indistinct punctures; prominent part of ventral spine of hypopygium short, with some short white setae.

\section{Male \\ Unknown.}

\section{Biology}

Only females are known. The adult wasps are known to induce galls on Cirsium vulgare (Asteraceae). Larvae overwinter in the gall, adults emerge next summer, in July. Another herb gall wasp, Isocolus cirsii Diakontschuk, 1987, induces galls in flower heads of Cirsium ukranicum Besser ex DC. (Asteraceae) (Melika 2006).

\section{Distribution}

Currently known only from Turkey (Ordu).

\section{Gall structure}

The gall is located on the stem (Fig. 9), in the form of an irregular swelling, 50-80 mm long. There are small larval cells in the typical form inside the stem. Multilocular.

\section{Discussion}

The current classification of the Cynipidae places all extant forms in a single subfamily (Cynipinae), with the majority of species falling into one of four tribes (Aylacini, Cynipini, Diplolepidini, Synergini) (Buffington et al. 2020). However, Cynipidae is now divided into twelve tribes (Ronquist et al. 2015). After the new classification, some genera of herb gall wasps previously classified within Aylacini were transferred to Aulacideini and Phanacidini (Buffington et al. 2020). This study brings the total number of the species belonging to the tribes Aulacideini and Phanacidini to 89 and 38, respectively. The three described species indicate the richness of the cynipid diversity in Turkey where is located in the Western Palaearctic. Moreover, future faunistic and taxonomic works in Turkey will continue to bring new species to the fauna of the country and the Western Palaearctic region.

\section{Acknowledgements}

We would like to thank Dr Mehmet Çiçek, who provided support for the identification of the plant species. We also thank Pamukkale University Scientific Research Project Unit (2019KRM004-063) for SEM images. This study was supported by a grant from the Scientific and Technological Research Council of Turkey (TÜBITTAK Project No: 117Z096).

\section{References}

Azmaz M. \& Katılmış Y. 2017. Updated species list of Cynipidae (Hymenoptera) from Turkey. Zootaxa 4303 (3): 361-378. https://doi.org/10.11646/zootaxa.4303.3.3

Azmaz M. \& Katılmış Y. 2020. A new species of herb gall wasp (Cynipidae, Aulacideini, Aulacidea) from Turkey. Zootaxa 4747 (2): 378-390. https://doi.org/10.11646/zootaxa.4747.2.9

Buffington M.L., Forshage M., Liljeblad J., Tang C.-T. \& van Noort S. 2020. World Cynipoidea (Hymenoptera): A key to higher-level groups. Insect Systematics and Diversity 4 (4): 1-69. https://doi.org/10.1093/isd/ixaa003

Harris R. 1979. A glossary of surface sculpturing. State of California, Department of Food and Agriculture, Occasional Papers in Entomology 28: 1-31. 
Melika G. 2006. Gall Wasps of Ukraine. Cynipidae. Vestnik Zoologii Supplement 21 (1-2): 1-300, 301-644.

Ronquist F., Nieves-Aldrey J.L., Buffington M.L., Liu Zh., Liljeblad J. \& Nylander J.A.A. 2015. Phylogeny, evolution and classification of gall wasps: the plot thickens. PLoS ONE 10 (5): 1-40.

https://doi.org/10.1371/journal.pone.0123301

Ronquist F. \& Nordlander G. 1989. Skeletal morphology of an archaic cynipoid, Ibalia rufipes (Hymenoptera: Ibaliidae). Entomologica Scandinavica Supplement 33: 1-60.

Ronquist F. 1995. Phylogeny and classification of the Liopteridae, an archaic group of cynipoid wasps (Hymenoptera). Entomologica Scandinavia Supplement 46: 1-74.

Manuscript received: 11 December 2020

Manuscript accepted: 13 April 2021

Published on: 5 July 2021

Topic editor: Nesrine Akkari

Desk editor: Marianne Salaün

Printed versions of all papers are also deposited in the libraries of the institutes that are members of the EJT consortium: Muséum national d'histoire naturelle, Paris, France; Meise Botanic Garden, Belgium; Royal Museum for Central Africa, Tervuren, Belgium; Royal Belgian Institute of Natural Sciences, Brussels, Belgium; Natural History Museum of Denmark, Copenhagen, Denmark; Naturalis Biodiversity Center, Leiden, the Netherlands; Museo Nacional de Ciencias Naturales-CSIC, Madrid, Spain; Real Jardín Botánico de Madrid CSIC, Spain; Zoological Research Museum Alexander Koenig, Bonn, Germany; National Museum, Prague, Czech Republic. 